\title{
Ministerio de Relaciones Exteriores de Brasil, Balanço de política externa 2003-2010. (www.itamaraty.gov.br).
}

\section{RESUMEN}

Dada la notoriedad y protagonismo que Brasil ha adquirido, particularmente en los últimos años, se ha generado un interés creciente en conocer su experiencia. ¿Qué ha hecho para llegar a ese desarrollo?, ¿es el inicio de su despegue definitivo o apenas una coyuntura favorable? En Brasil se han hecho públicos diversos estudios, algunos desde el interior del gobierno y otros desde sectores académicos, que enfatizan unos los logros, otros los pendientes.

En el caso de la política exterior, campo de particular importancia al ser la expresión de las aspiraciones brasileñas de posicionarse en el cambiante escenario mundial, el Ministerio de Relaciones Exteriores (MRE) elaboró un documento que contiene un inventario de los logros alcanzados en materia internacional por el gobierno de Lula en sus ocho años de mandato.

Según dicha fuente, la pauta que orientó su administración en el ámbito externo fue que Brasil "debe asumir un papel creciente en el escenario internacional, proyectando una imagen externa altiva y soberana" (p. 18), enfocando sus esfuerzos principalmente hacia América del Sur (región que identifica como eje prioritario). En la práctica esto ha proporcionado a Brasil una plataforma para proyectarse hacia la meta de ser reconocido, no sólo como potencia regional, sino como un nuevo e imprescindible actor global ("fortalecimiento de la capacidad de actuación de Brasil en otros foros internacionales", p. 18).

Son varios los aspectos que se desprenden de la lectura del documento:

a) Para alcanzar su objetivo de consolidar su posición como importante actor emergente está dispuesto a invertir recursos (financieros, humanos, materiales) como expresión de su voluntad política de opinar 
y participar en la solución de temas de la agenda global. Es destacada su participación en misiones de paz de la onu (particularmente en Haitî), sus aportaciones en apoyo del Estado Palestino y sus contribuciones a favor de países africanos y centroamericanos como Nicaragua y El Salvador. En América del Sur ha invertido en la construcción de obras de infraestructura que, en algunos casos, son totalmente costeadas con recursos brasileños.

b) Esta inversión se revierte: $i$ ) en apoyos políticos de los países favorecidos, que tienden a respaldar las aspiraciones brasileñas (asegura tener el apoyo de 89 países en su propósito de convertirse en miembro permanente del Consejo de Seguridad de la onu); ii) en mayores flujos comerciales, en particular de sus exportaciones (aunque los superávit han ido decreciendo en los últimos años, cerró 2010 con un saldo positivo de alrededor de US20 mil mdd); y iii) en una creciente presencia en el exterior de empresas brasileñas (públicas y privadas) apoyadas por el impulso gubernamental, como sería el caso de la minera Vale, de las constructoras Odebrecht y Gutiérrez-Andrade, así como Petrobras, Embraer (fabricación de aviones) y Embrapa (investigación agropecuaria).

c) Su pertenencia a grupos como BRICS e IBAS ha favorecido su posicionamiento en el plano internacional. Ha ganado espacio en los organismos financieros internacionales, como el BM y el FMI, donde ahora tiene una mayor participación en la toma de decisiones.

d) Si la forma es fondo, puede ser significativo que en el cuerpo del documento, los países que en lo individual ocupan un lugar destacado son Estados Unidos y China, con los que parece buscar una relación bilateral estratégica.

Luego de una breve introducción, el documento hace un recuento de logros (O QUE FOI FEITO), dividiendo su reseña en áreas geográficas en el siguiente orden: a) América del Sur, Central y Caribe; y b) América del Norte, Europa, África, Oriente Medio, Asia y Oceanía. Incluye un apartado intitulado Gobernanza Global y Temas Multilaterales en el que aparecen los principales organismos y me- 
canismos multilaterales políticos y financieros y asuntos como operaciones de paz de la onu y la integración latinoamericana.

Se mencionan a continuación algunos datos que contiene el documento que se reseña y que confirmarían las apreciaciones propuestas en los párrafos anteriores:

\section{AmÉriCA del Sur, Central y Caribe:}

- Promovió la creación de la unasur (2008), que agrupa a todos los países sudamericanos, donde tiene una influencia indiscutible por ser el país de mayor dimensión territorial y cuya economía sobrepasa con mucho las de sus vecinos. La misma situación se observa en el MERCOSUR (creado en 1991 con la participación de Argentina, Uruguay, Paraguay y Brasil). Un ejemplo de ello es el reciente nombramiento del embajador Samuel Pinheiro Guimarães (ex secretario de Asuntos Estratégicos en el gobierno del presidente Lula), como alto representante general del MERCosur que cumplirá funciones de articulación política, formulación de propuestas y representación de las posiciones comunes del bloque. - Ha buscado extender y fortalecer sus vínculos con el resto de América Latina y el Caribe. Desde 2004 es observador en la Comunidad del Caribe (CARICOM), ha estrechado sus lazos con Centroamérica a través del Sistema de Integración Centroamericana (SICA) y ha establecido relaciones especiales de cooperación con El Salvador y Nicaragua. Con el Caribe, ha avanzado en el proceso de convertirse en socio regional (contribuyente) del Banco de Desarrollo del Caribe y ha establecido embajadas residentes en todos los países de la CARICOM. En diciembre de 2008 convocó a la I Cumbre de América Latina y el Caribe sobre integración y desarrollo (CALC) que junto con el Grupo de Río constituyen los mecanismos con mayor representatividad latinoamericana, y cuyo trabajo conjunto derivó en febrero de 2010 (Cumbre de la Unidad en Cancún, México) en la creación de la Comunidad de Estados Latinoamericanos y Caribeños.

- En el periodo 2003-2009, las exportaciones brasileñas hacia América del Sur aumentaron 165\% frente a 149\% de sus importaciones, con un saldo a favor de Brasil por US7.9 billones de dólares -bdd-, que corresponde a 31.4\% del superávit total del país. En ese periodo dicha región se convirtió en el principal destino de las inversiones de empresas brasileñas en el exterior. Con los países de Cen- 
troamérica y México el superávit fue de US490 millones de dólares -mdd- y con los países del Caribe, de US4.5 bdd.

\section{América del Norte, Europa, África, Oriente Medio, Asia y Oceanía}

- EU: se destaca el establecimiento del mecanismo bilateral Diálogo Alianza Global en marzo de 2010 por los cancilleres Clinton y Amorim. Se trasluce el interés brasileño de incorporar en su relación con Estados Unidos, no únicamente temas bilaterales como la balanza comercial (favorable a uSA al cierre de 2010 por un monto de US7.7 bdd) y asuntos energéticos (particularmente los escollos norteamericanos al etanol brasileño). También incluye en la agenda temas regionales y globales en los que Brasil se muestra interesado (proceso de paz en Medio Oriente, Honduras, OEA). De acuerdo con declaraciones recientes del actual embajador de Estados Unidos en Brasil, Thomas Shannon, ese país reconoce a Brasil su rol de actor global. En el plano comercial el gobierno brasileño destaca su no dependencia de Estados Unidos al tener un comercio diversificado con las diferentes regiones del mundo. No obstante, se reconoce que dicho país continúa siendo el principal inversionista extranjero en Brasil.

- Europa: alianza estratégica con Brasil desde 2007. Como bloque, Europa se convirtió en el segundo mayor socio comercial de Brasil, sólo detrás de Asia: el intercambio comercial pasó de US30 bdd en 2003 para US74 bdd en 2009. Cuatro de los cinco mayores inversionistas son europeos: Países Bajos, España, Alemania y Francia que juntos constituyen $45 \%$ de ingresos de capital extranjero.

- África: el acercamiento a África es una de las principales vertientes de la política exterior brasileña desde 2003 (cuenta con más de 30 embajadas en ese continente). Los beneficios para Brasil son el acceso a nuevos mercados, oportunidades económicas ventajosas y mayor influencia en foros multilaterales. El intercambio comercial se quintuplicó pasando de US5 bdd en 2002 a casi US26 bdd en 2008. Las empresas brasileñas han ganado presencia: la minera Vale está en casi todos los países del continente, Petrobras en Angola, Libia, Tanzania, Namibia y Nigeria; las constructoras Andrade Gutiérrez y Odebrecht construyen carreteras en Camerún, Guinea, Argelia, Mauritania y Ghana, y puertos y aeropuertos en Libia y Mozambique, en tanto que Embraer vende aviones a Angola 
y África del Sur. En educación, Brasil ha establecido un generoso programa de becas: entre 2003 y 2010 alrededor de 4300 estudiantes de 20 países africanos hicieron estudios de grado y 237 de posgrado. Con el apoyo decidido de Brasil que, en contraste con sus vecinos sudamericanos, tiene una clara vocación e intereses concretos en el continente africano, se estableció en 2006 la Cumbre América del Sur-África que agrupa a 65 jefes de Estado y de Gobierno de los dos continentes.

- Oriente Medio: Brasil, interesado en involucrarse en el proceso de paz con Israel, defiende la participación de nuevos interlocutores en el mismo. Para mostrar su disposición política, ha hecho contribuciones financieras, como la donación de US20 mdd para la reconstrucción de los territorios palestinos y el fortalecimiento de la Autoridad Nacional Palestina. El 3 de diciembre de 2010 el gobierno brasileño hizo público su reconocimiento del Estado Palestino con las fronteras existentes en 1967, gesto que fue emulado por la mayoría de los países sudamericanos. Esto en los meses previos de la Cumbre América del Sur-Países Árabes (ASPA) que tendría lugar a mediados de febrero de 2011 en Lima, pero que fue aplazada por la convulsa situación interna que hoy priva en Egipto y en otros países árabes. Es conocida la posición del gobierno del presidente Lula en relación con Irán que ha ido en contravía de la posición norteamericana y europea. La intensa actividad diplomática y el acercamiento de Brasil a la región se ha reflejado en un aumento del comercio que pasó de US4.4 bdd en 2003 para US10.6 bdd en 2009.

- Asia y Oceanía: como región, Asia se convirtió en el principal socio comercial de Brasil en 2009. El intercambio comercial con la totalidad de países de la región pasó de US20.5 bdd en 2003 a US76 bdd en 2009, de los cuales US40 bdd fueron exportaciones brasileñas. Individualmente, China es su principal socio comercial (intercambio comercial por US36.1 bdd) y el mayor mercado para sus exportaciones, integradas principalmente por productos primarios. Las crecientes inversiones chinas en Brasil se ubican en la minería, la siderurgia, el petróleo y la transmisión de electricidad. Mantiene superávit comercial con China, pero tiene comercio deficitario con Corea del Sur, Tailandia e India. 


\section{GOBERNANZA GLOBAL Y TEMAS MULTILATERALES}

- onu y Consejo de Seguridad (CS): una de las grandes aspiraciones de Brasil es integrar el cs como miembro permanente. Junto con Alemania, Japón y la India integra el llamado $G 4$ para impulsar la reforma del consejo ampliando su representatividad al incluir precisamente a los cuatro países que integran el grupo. En el documento se señala que Brasil cuenta con el apoyo de 89 de los 192 miembros de la ond, incluyendo Francia y Reino Unido que son miembros permanentes del cs, lo cual implica que hasta ahora no ha conseguido el respaldo de los otros tres permanentes: $\mathrm{EU}$, China y Rusia. En Brasil se espera que el presidente Obama, quien ha anunciado una visita oficial para el mes de marzo a dicho país, se pronuncie sobre el particular, tomando en consideración que recientemente expresó su apoyo a la India.

- FMI, BM y G20: la reforma del Fondo Monetario Internacional y del Banco Mundial son parte central del proceso de reforma de la arquitectura financiera internacional. Brasil, en calidad de destacado país emergente, ha defendido la transferencia de poder de voto de los países desarrollados a los países en desarrollo, para que cada miembro tenga peso de voto en relación con su peso relativo en la economía mundial. En abril de 2010 el BM transfirió 3.13\% de las cuotas para los países en desarrollo que pasaron a sumar $47.2 \%$ en su conjunto; el peso de Brasil pasó de 2.06 a 2.24\%.

- IBAS: establecido en junio de 2003 por iniciativa brasileña, el foro IBAS (India, Brasil y África del Sur) es un mecanismo de coordinación entre 3 países emergentes que comparten la característica de ser democracias multiétnicas y multiculturales, que pretenden contribuir en la construcción de una nueva arquitectura internacional.

- Operaciones de Paz de la onu: en enero de 2003 Brasil participaba en dos misiones de paz con 79 hombres. En septiembre de 2010 integraba 9 misiones con 2258 elementos.

\section{COMENTARIO FINAL}

El cambio de gobierno en Brasil que tuvo lugar el $1^{\circ}$ de enero de 2011, en el que la presidenta Dilma Rousseff (también miembro del PT) relevó al presidente Luiz Inácio Lula da Silva, ha abierto la interrogante de si se mantendrá la misma línea 
en materia de política exterior. Aunque es muy temprano para saberlo, en los dos primeros meses de gobierno la señora Rousseff ha hecho manifestaciones que parecerían significar una diferencia con su antecesor en algunos temas concretos: uno es el caso de Irán, en el que se ha pronunciado por el respeto de los Derechos Humanos y, otro, todavía en ciernes, es el posible giro para buscar una relación de mayor cooperación e intercambio con Estados Unidos. Otro elemento que podría incidir en la intensidad de la política exterior brasileña es la situación económica interna. Si bien se ha registrado un crecimiento positivo en los últimos años, al iniciarse el gobierno de la presidenta Rousseff, ésta ha anunciado un corte al presupuesto 2011 de alrededor de $\mathrm{R} \$ 50$ billones de reales para equilibrar el gasto público, reducir la inflación y las expectativas de mayores tasas de interés que coadyuvan a la revalorización del real, que para algunos (como los empresarios exportadores) resulta excesiva.

Sergio Saavedra Meléndez Jefe de Cancillería de la Embajada de México en Brasil 